\title{
AOR
}

Selected Papers of \#AoIR2020:

The $21^{\text {st }}$ Annual Conference of the

Association of Internet Researchers

Virtual Event / 27-31 October 2020

\section{BURYING THE DEAD (USERS): A LIFE OF DATA WITHIN LIMITS}

\author{
Sarah Welsh \\ The University of Texas at Austin
}

Technological innovation depends on earthly resources. As such, the drive to continuous growth that has propelled technology forward is also in direct competition with a planet that is reaching capacity. This expansion and consumption model has both supported and neglected the data of the dead, which both proliferates and languishes. For example, as researchers across disciplines have noted, the dead may soon outnumber the living on social media (Karppi, 2018; Öhman \& Watson, 2019). But while questions about digital remains are "critically needed" (Öhman \& Watson, 2019, pp. 8), those questions should attend not only to social media profiles but also to the life cycles of data. This paper considers environmental and resource-related questions about the traces we leave when we depart. To do this work, a theoretical methodological approach following the Computing within LIMITS model (Nardi et al., 2018) is employed to consider the accumulation of data that remains after users have departed from their earthly (and digital) lives. LIMITS is a sustainability model that asks researchers to (1) question growth, (2) consider models of scarcity, and (3) reduce energy and material consumption. That is, this paper questions the life of digital data that can be maintained and can even grow after a user passes on. In addition to questions about mourning, memorializing, and archiving the dead, the LIMITS model prompts ethical questions about how to bury our dead data responsibly and sustainably in the face of exponential growth.

\section{Maintaining Digital Remains}

Increasing attention has been paid to technologies for grief, end of life, and digital possessions (Sas et al., 2019), and also to digital remains as big data (Karppi, 2018; Öhman \& Watson, 2019). However, these perspectives often focus on the (important) question of how digital remains are mediated by corporate interests (as Facebook profiles especially), and less on the environmental impact of the mass-scale preservation required for such a model. Many corporate responses to dead profiles depend on more profiles accumulating, and some digital services even allow the dead 
to "stay in touch" with their descendants after their death. This paper poses such responses to this problem as growth-oriented and unsustainable in the long-term, using the LIMITS model to show how the maintenance of digital remains does not always contribute to well-being or allow for flourishing. Services for digital remains that are most in-line with the LIMITS model are those that Öhman \& Floridi (2018) term "information management services" which ensuring that "assets are passed on (or destroyed) on death" (pp. 318), rather than being given new life, or in other cases even sustained. Some digital remains and languishing pages may not seem like much environmental strain, but every piece is a part of the larger whole. As more humans are starting online lives, the services that address death often promote (unsustainable or unnecessary) digital growth.

\section{Environmental Scarcity}

Digital remains become digital rubbish (Gabrys, 2011) when they are not maintained, useful, or are left to languish. For Gabrys, while data may be transient, the "rapidity of technological progress leads to enduring and toxic electronic materials" (pp.17). Across platforms, across users, across systems, all digital actors are implicated in technological progress and "growth" writ large. While big data may help provide the scientific knowledge necessary for environmental problems like climate change, data centers consume vast amounts of energy, water, and other resources in order to maintain the data that they sustain (Gmach et al., 2010). As such, it would seem that sustainable, responsible data deletion (and forgetting) is in order as a viable solution for the everyday user. Data belonging to deceased users might be valuable to corporations, but aside from a means to navigating grief or mourning, may be less so to relatives or friends of the deceased. Additionally, one's personal digital remains may be distributed across platforms, and thus the solution affects multiple stakeholders: relatives, friends, corporations, data centers, and so forth. This to say that the data of the deceased is valuable to multiple stakeholders, but approaches that provide an environmentallysustainable model are the most ethically responsible especially in this moment of planetary crisis.

\section{Reducing Energy Consumption through Ephemerality}

When and how can we learn to let go? Social media platforms have become "global repositories of our digital memories" (Mayer-Schönberger, 2018) rife for data harvesting, for expansion, for growth. And digital technology has been designed to discourage forgetting — as accidental deletion, crashes, hardware failures, and so forth-in order to protect what has been stored, or in this case, to preserve and memorialize lives that have been lived online. But if forgetting has value alongside memory (Ricoeur, 2004), what are we to make of the data of the dead? Digital remains of the deceased are a tangible example of hotly debated archival and preservation-focused questions about memory and forgetting. Such an accumulation might do well to embrace ephemerality and promote deletion or at least strategic forgetting. Life is inherently ephemeral, and online our data might find a way to replicate that, which would respect LIMITS. Looking to ephemeral messaging functions provides a sustainable model that reflects life's 
inherent ephemerality, allows for and even encourages decomposition and disappearance, and might be ethically extended to the digital traces that persist after death.

\section{Conclusion}

While the futures of internet platforms and physical data centers are of course uncertain, what is more certain is that digital remains do not decompose, and environmental resources are scarce. Because there is no end in sight for death as a force of life, and because digital media technologies proliferate among users across the globe, the goals of this paper are twofold: to review the sustainability of solutions to the afterlife of digital remains, and to outline solutions that allow digital zombies to live within LIMITS, or to exist in the same ephemeral spaces as our physical bodies. In so doing, this paper questions growth as a viable environmental model, and argues that deletion and forgetting are the most sustainable —if not counterintuitive-options for digital remains.

\section{References}

Gabrys, J. (2011). Digital Rubbish: A Natural History of Electronics. University of Michigan.

Gmach, D. et al. (2010). "Profiling Sustainability of Data Centers," Proceedings of the 2010 IEEE International Symposium on Sustainable Systems and Technology, Arlington, VA, 2010, pp. 1-6.

Karppi, T. (2018). Disconnect: Facebook's Affective Bonds. University of Minnesota Press.

Mayer-Schönberger, V. (2018). Remembering (to) delete: forgetting beyond informational privacy. In Thouvenin, F., Hettich, P., Burkert, H, \& Gasser, U. Remembering and Forgetting in the Digital Age. (pp 118-123). Springer

Nardi, B., Tomlinson, B., Patterson, D. J., Chen, J., Pargman, D., Raghavan, B., \& Penzenstadler, B. (2018). Computing within limits. Communications of the ACM, 61(10), 86-93. https://doi.org/10.1145/3183582

Öhman, C. J., \& Watson, D. (2019). Are the dead taking over Facebook? A Big Data approach to the future of death online. Big Data \& Society. https://doi.org/10.1177/2053951719842540

Öhman, C.J., \& Floridi, L. (2018). An ethical framework for the digital afterlife industry. Nature Human Behavior. DOI.org/10.1038/s41562-018-0335-2 .

Ricoeur, P. (2004). Memory, History, Forgetting. Chicago: University of Chicago Press. 
Sas, C., Schreiter,M., Büscher, M., Gamba, F. \& Coman, A. (2019). Futures of digital death: Past, present and charting emerging research agenda. Death Studies. https://doi.org/10.1080/07481187.2019.1647643 